\title{
Utilization of Synthetic Zeolite for Removal of Anionic Dyes
}

\author{
Rasha M. Abd El Wahab, Doaa M. El-Mekkawi, F.M. \\ El Dars", A.B. Farag* and M.M. Selim" \\ Physical Chemistry Department, National Research Centre \\ and "Chemistry Department, Faculty of Science, Helwan \\ University, Cairo, Egypt.
}

\begin{abstract}
7 HE REMOVAL performance of highly colored soluble organic 1 pollutants in water has been investigated. Comparative adsorption studies of some anionic dyes on commercially zeolite $\mathrm{X}$ and zeolite $\mathrm{X}$ powder prepared from Egyptian kaolin have been studied. Brilliant blue FCF (BL), brilliant black PN (BB), eriochrome black T (EBT) and ponceau 3R (P3R) were introduced as models for organic pollutants of different structures. For comparison, the properties of the synthetic zeolite and commercial grade zeolite, such as crystallinity, thermal stability and cation exchange capacity using $\mathrm{XRD}$, DSC and atomic absorption spectroscopy, respectively were conducted. UV/visible spectroscopic measurements have been used to determine the amount of adsorbed dyes by zeolites. The adsorption capacities for batch method were recorded. The influential parameters, such as initial $\mathrm{pH}$ value of the solution, temperature, adsorbate concentration and ion exchange on the adsorption process were studied. The suitability of Langmuir and Freundlich isotherms to the equilibrium data was investigated in the solid-liquid system. In all the adsorption experiments, the variation of adsorption capacities were recorded and explained in terms of both zeolite behaviour and dyes structures. Attempts to regenerate the adsorbents physically (at high temperature) were also made and the adsorptive properties of the recovered zeolite have been provided.
\end{abstract}

Keywords: Adsorption, Anionic dyes, Zeolite and Egyptian kaolin.

The removal of organic dyes in waste effluents is of environmentally importance and they are widely used in industries such as textiles, paper, rubber, plastics and cosmetics ${ }^{(1)}$. Many of the dyes, used in these industries are generally toxic, nondegradable, stable, and even carcinogenic ${ }^{(4)}$. The coloration of water caused by highly coloured soluble dyes inhibits sunlight penetration into the stream so as to reduce the photosynthetic reaction ${ }^{(12)}$. During the last few years, various methods, such as aerobic and anaerobic microbial degradations, electrochemical treatment, hydrogen peroxide catalysis, chemical oxidation, reverse osmosis, coagulation, and flocculation, have been investigated for the removal of organic dyes. Most of these methods suffer from a number of disadvantages, such as high

\#Corresponding author E-mail: mmaselim@yahoo.com 
capital, operational costs, and the problem of unsuccessful removal of the coloration from wastewater ${ }^{(2)}$.

Adsorption is one of the effective methods for dye removal ${ }^{(8)}$, which has been carried by using adsorbents, such as peat, palm-fruit, zeolites, fly ash, montmorillonite and activated carbon ${ }^{(1)}$. Zeolites are of prime importance as adsorbents for many industrial processes, due mainly to their shape selectivity and acid sites ${ }^{(3)}$. Considering discharged volume, this has encouraged research into developing the low-cost and effective adsorbents to purify water contaminated with dyes ${ }^{(2,8)}$.

The aim of this study is to examine the effectiveness of synthetic zeolitic adsorbents. Both commercial (ZX) and hydrothermally prepared Zeolite X (ZXK) from Egyptian kaolin have been used in removing dyes from aqueous solutions. Different anionic dyes with different structures such as Briliant blue FCF (BL), Briliant black PN (BB), Eriochrome black T (EBT) and Ponceau 3R (P3R) were chosen for the adsorption studies because of their toxicity to the environment and to the human health.

The kinetic of the process and the adsorption capacity of the adsorbents were determined on the adsorption process. Batch method has been used in our investigations. The influences of various parameters on the dye removal performance by original adsorbents in addition to the regeneration process were investigated and also studied for comparison. The parameters studied in this study included initial $\mathrm{pH}$ value, temperature, adsorbate concentration and ion exchange effect.

\section{Experimental}

\section{Adsorbate}

The following table represents the anionic dyes which have been introduced in the present study as models for organic dye pollutants:

Different concentrations of dye solutions were prepared by dissolving a weighed quantity of these dyes in distilled water. The initial $\mathrm{pH}$ of the dye solution was adjusted to the desired value by adding $\mathrm{HCl}$ and $\mathrm{NaOH}$ solution and measured with $\mathrm{pH}$ meter.

\section{Adsorbent}

Commercially available zeolite $\mathrm{X}$ (ZX) obtained fromunion carbide international company (molecular sieves) $\mathrm{USA}^{(13)}$, and zeolite $\mathrm{X}$ powder prepared from Egyptian kaolin (ZXK) were used for the adsorption experiments. $\mathrm{Na}-\mathrm{X}$ zeolite was prepared by hydrothermal treatment of Egyptian kaolin with alkali solution and sodium silicate at $100-120{ }^{\circ} \mathrm{C}$ for $8 \mathrm{hr}$ according to the Egyptian patent ${ }^{(7)}$. 
TABLE 1. Structures, optical properties and specifications of dyes under investigation.

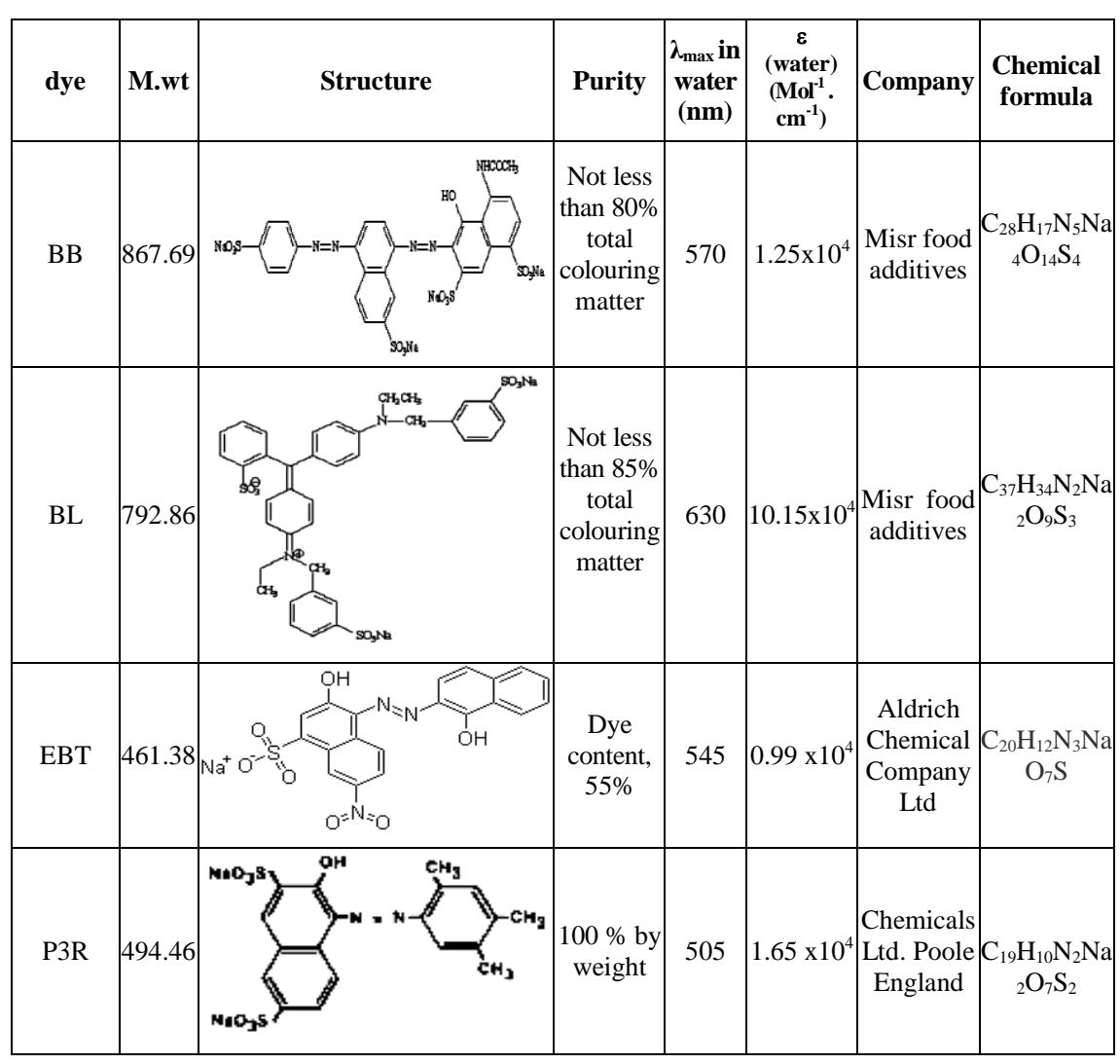

Preparation of ion-exchanged zeolites

Ion exchange processes of zeolites were carried out using $\mathrm{Ba}^{+2}, \mathrm{Mg}^{+2}$ and $\mathrm{Ca}^{+2}$ solutions. Batch experiments were conducted using $5 \mathrm{~g}$ of zeolite $\mathrm{X}$ (the two types) with $100 \mathrm{ml}$ of solutions containing metal ions of concentrations 0.5 $\mathrm{N}$ of $\mathrm{CaCl}_{2}\left(95 \%\right.$, Sisco Research Laboratories PVT. LTD, India), $\mathrm{MgSO}_{4} \cdot 7 \mathrm{H}_{2} \mathrm{O}$ (99\% Lab Rasayan) and $\mathrm{Ba}(\mathrm{NO} 3)_{2}(99.9 \%$, VEB Laborchemie Apolda). At constant temperatures $\left(25^{\circ} \mathrm{C}\right)$ in a conical flask $(250 \mathrm{ml})$, the mixtures were stirred for $3 \mathrm{hr}$. After each ion exchange the solid material was filtered, washed with deionized water, and dried at $100^{\circ} \mathrm{C}$ in air. This process was repeated twice. The exact concentration of metal ions and filterable metal concentrations for each cycle were determined by AAS (thermoelemental, solar S4, England atomic absorption spectrophotometer).

The amount of metal ion exchange $(\mathrm{mg})$ per one gram zeolite

$$
=\left(C_{i}-C_{f} / C_{i}\right) / M
$$


where $C_{i}$ and $C_{f}$ are the concentrations of the metal ion in initial and final solutions (mg. $\left.\mathrm{L}^{-1}\right)$, respectively. $M$ is the amount of adsorbents per liter $\left(\mathrm{g} . \mathrm{L}^{-1}\right)$.

\section{Characterization}

$X$-ray diffraction $(X R D)$

X-Ray diffraction patterns were collected using a Bruker D8 advance instrument with $\mathrm{CuK} \alpha 1$ target with secondary monochromator $40 \mathrm{KV}, 40 \mathrm{~mA}$.

\section{$U V-$ Visible measurements}

The absorption spectra of different dyes were measured using UV-Visible, UV 2401PC record spectrometer, Shimadzu.

\section{Differential Scanning Calorimetry (DSC)}

Thermal parameters of the samples were determined by Differential Scanning Calorimeter (DSC), Perkin Elmar equipped with a DSC-7 data station, and specimen $(\approx 5 \mathrm{mg})$ of the sample is used for DSC measurements. The measurements were carried out in $\mathrm{N}_{2}$ atmosphere at a heating rate of $10{ }^{\circ} \mathrm{C} \mathrm{min}{ }^{-1}$.

\section{Batch adsorption experiments}

The study of adsorption kinetics and equilibrium is essential in supplying the fundamental information required for the design and the operation of adsorption equipments for wastewater treatment. All adsorption experiments were performed in a batch-stoppered glass bottles $(100 \mathrm{ml})$ at room temperature with stirring for $24 \mathrm{hr}$.

\section{Kinetic studies}

The $1 \mathrm{~g}$ of adsorbents was left in contact with $100 \mathrm{ml}$ of the dye solutions (different concentration) at the initial $\mathrm{pH}$ of (5.4-6.6 depending on the dye) at room temperature. Kinetic of adsorption was determined by analyzing the adsorptive uptake of dyes spectrophotometrically from aqueous solution at different time intervals (15-1440 min).

\section{Adsorption isotherm}

At temperatures $\left(20,30,35,40,50{ }^{\circ} \mathrm{C}\right), 10 \mathrm{ml}$ of the used dyes solutions at different concentration mg. $\mathrm{L}^{-1}$ were agitated with adsorbents $(0.1 \mathrm{~g})$. The amount of dye adsorbed on the adsorbents $q_{e}\left(\mathrm{mg} \cdot \mathrm{g}^{-1}\right)$ was calculated using the following expression: $:^{(1,2,4,5,8,9,10,11)}$

$$
q_{e}=\left(C_{o}-C_{e}\right) \cdot M
$$

where, $C_{o}$ and $C_{e}$ are the initial and equilibrium dyes concentrations of the test solution (mg. $\left.\mathrm{L}^{-1}\right)$, respectively, $\mathrm{M}$ is the amount of adsorbents per liter $\left(\mathrm{g} . \mathrm{L}^{-1}\right)$

\section{Adsorbents regeneration}

In wastewater treatment, reuse and recovery of the spent adsorbents could play important role. Keeping this in view, experiments were carried out using the

Egypt. J. Chem. 53, No. 3 (2010) 
heat treatment (physical treatment) to regenerate the dye-saturated adsorbents at 300 and $550^{\circ} \mathrm{C}$ for $4 \mathrm{hr}$. The adsorption capacity of regenerative and original adsorbents was investigated in batch experiments for comparison.

\section{Results and Discussion}

\section{Characterization of adsorbents}

The XRD patterns for both commercial and synthetic zeolites in Fig. 1 illustrate that the used adsorbents are faujasite type $\mathrm{X}$ zeolites.

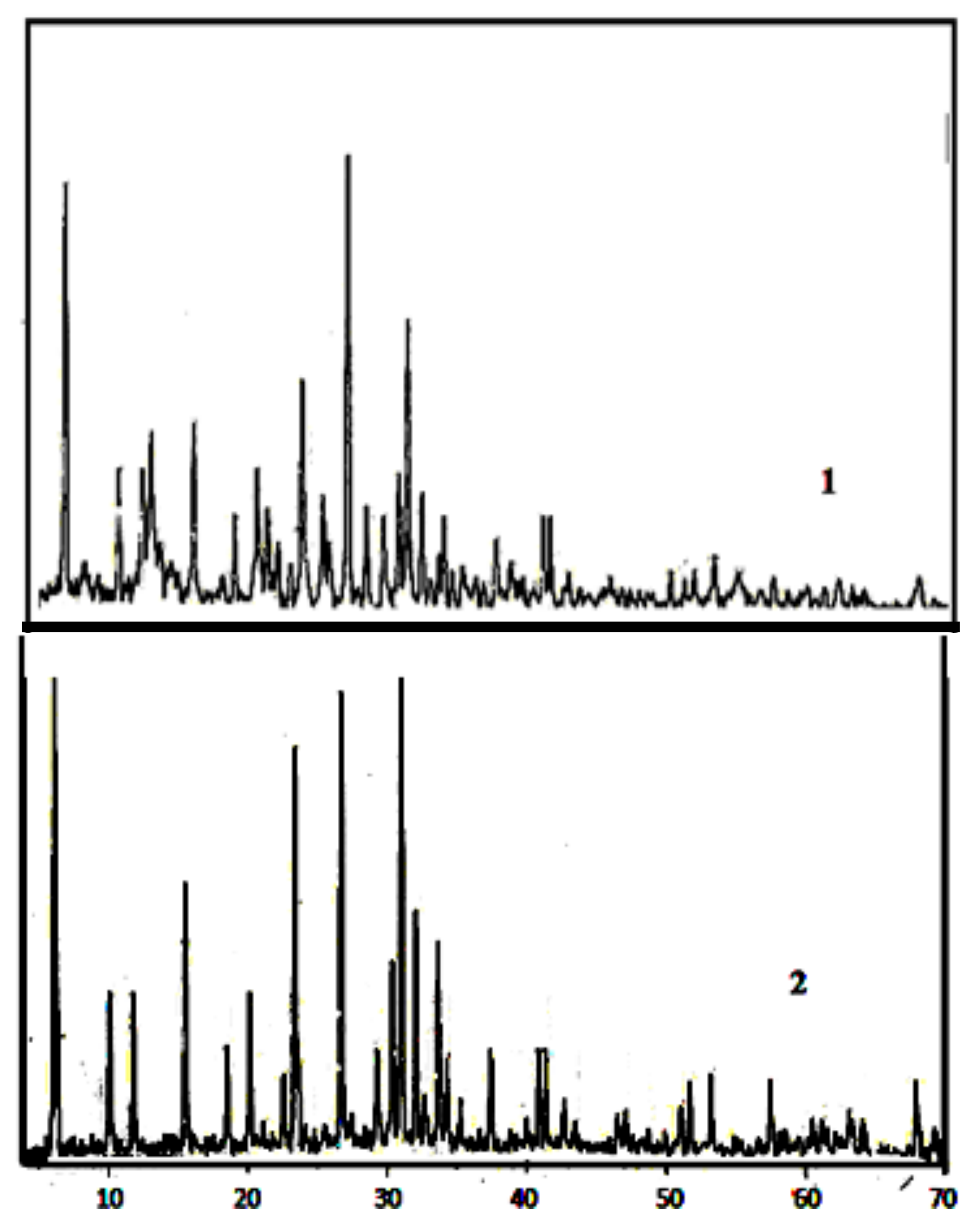

Fig. 1. XRD patterns of adsorbents (1) ZXK and (2) ZX.

DSC measurements were carried out on zeolites before and after dye adsorption procedures. Endothermic peaks appear in the region of $200-300{ }^{\circ} \mathrm{C}$ for zeolite after adsorption. The endothermic reaction may be attributed to the presence of zeolitic water as well as thermal degradation of organic dye. Further 
increase in temperature till $500^{\circ} \mathrm{C}$ shows no more peaks. For zeolite regeneration, zeolite samples were heated at 300 and $550^{\circ} \mathrm{C}$ and the adsorption capacity of the regenerated dyes were studied.

\section{Adsorption kinetics}

A series of experiments were carried out to find the optimum time to reach equilibrium. The experiments were performed against time $(15,30,60,120,180$, $240,300,360,420,1320$ and $1440 \mathrm{~min}$ ) at a constant dye concentration and a solid/liquid ratio of $10 \%$. The results are given in Fig. 2 for both zeolites. As shown in Fig. 2, as the conditioning time increases, the amount of adsorption of anionic dyes into the zeolite increases significantly. It is evident that time required for maximum adsorption varies according to the dye. On the other hand, for each dye both commercial and synthetic zeolite show the same adsorption kinetic trend.

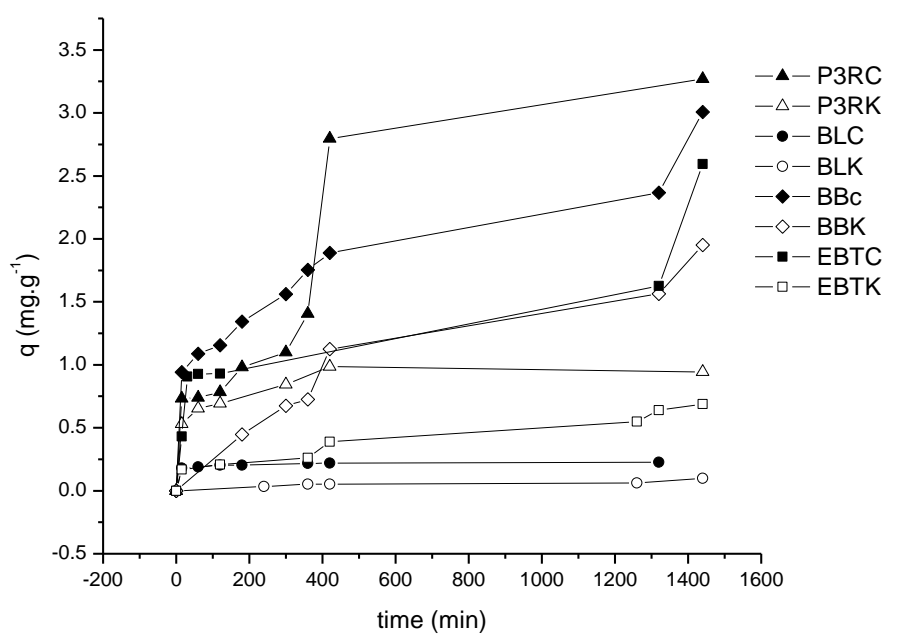

Fig. 2. Effect of conditioning time on the adsorption of reactive azo dyes into zeolite: Filled symbols represent (ZX) and empty symbols represent (ZXK).

The data obtained show that BB, EBT, P3R and BL were adsorbed into commercial zeolite with recoveries that will be discussed later.

There are essentially three steps in the adsorption process by porous adsorbents: (1) solute transfer from the bulk solution to the external surface of the adsorbent through a liquid boundary layer (liquid film diffusion), (2) solute transfer from the adsorbent surface to the intraparticle active sites (intraparticle diffusion), and (3) interactions of the solute with the available sites on both the external and internal surfaces of the adsorbent (chemical reaction). One or more of the above-mentioned steps may control the rate at which the solute is adsorbed and the amount of solute that is adsorbed onto the adsorbents. To identify the step governing the overall removal rate of the adsorption process, the models

Egypt. J. Chem. 53, No. 3 (2010) 
given by Boyd et al. and Reichenbery were applied. Liquid film diffusion, intraparticle diffusion, and chemical reaction are described in the following equations, respectively: ${ }^{(2)}$

$$
\begin{aligned}
& \ln (1-F)=-k_{d} t \\
& 1-3(1-F)^{2 / 3}+2(1-F)=k_{i} t \\
& 1-(1-F)^{1 / 3}=k_{c} t
\end{aligned}
$$

where $F\left(F=\mathrm{q}_{\mathrm{t}} / \mathrm{q}_{\mathrm{e}}\right)$ and $\mathrm{q}_{\mathrm{t}}\left(\mathrm{mg} \cdot \mathrm{g}^{-1}\right)$ are the amount of dye adsorbed on the adsorbents and the adsorption fractions at time $t$, respectively, and $k$ is the diffusion coefficient at $25^{\circ} \mathrm{C}$. Figure 3 shows liquid film diffusion, intraparticle diffusion, and chemical reaction models fitting to the experimental data, respectively. Correlation coefficient $(R)$ between the experimental data and the three models as well as the rate constant values indicate that the chemical reaction step or intraparticle diffusion can be considered as a rate determining step for adsorbents ZXK and ZX (Table 2). This could be due to the repulsion

\begin{tabular}{|c|c|c|c|c|c|c|c|}
\hline dye & Zeolite & $\mathbf{k}_{\mathrm{d}}$ & $\mathbf{k}_{\mathbf{i}}$ & $\mathbf{k}_{\mathrm{c}}$ & $\mathbf{R}_{d}$ & $\mathbf{R}_{\mathbf{i}}$ & $\mathbf{R}_{\mathrm{c}}$ \\
\hline EBT & \multirow{4}{*}{ ZX } & 0.01237 & 0.0007 & 0.0006 & 0.99830 & 0.99881 & 0.99773 \\
\hline BB & & 0.0009 & 0.0003 & 0.0006 & 0.97017 & 0.97274 & 0.99215 \\
\hline P3R & & 0.00417 & 0.0002 & 0.0007 & 0.94178 & 0.94918 & 0.98474 \\
\hline BL & & 0.01321 & 0.0009 & 0.0004 & 0.97667 & 0.98459 & 0.97991 \\
\hline EBT & \multirow{4}{*}{ ZXK } & 0.0154 & 0.0004 & 0.0004 & 0.95502 & 0.94857 & 0.96272 \\
\hline BB & & 0.0012 & 0.0003 & 0.0007 & 0.99933 & 0.99140 & 0.99410 \\
\hline P3R & & 0.0062 & 0.0016 & 0.0005 & 0.91896 & 0.95632 & 0.98518 \\
\hline BL & & 0.01625 & 0.0007 & 0.0007 & 0.96588 & 0.98488 & 0.99766 \\
\hline
\end{tabular}
between the anionic dyes and the negative charge inside zeolite pores.

TABLE 2. Parameters obtained from adsorption kinetics of dyes on $\mathrm{ZX}$ and ZXK.

where $\mathrm{k}_{\mathrm{d}}, \mathrm{k}_{\mathrm{i}}$ and $\mathrm{k}_{\mathrm{c}}$ are diffusion coefficient obtained from liquid film diffusion, intraparticle diffusion, and chemical reaction, respectively and $R_{d}, R_{i}$ and $R_{c}$ are their correlation coefficient, respectively.

Lagergren first-order model and Ho' Pseudosecond- order model are two important models applied for solid-liquid adsorption. The following expressions were used to describe two models, respectively: ${ }^{(1,2,5,8,11)}$

$$
\begin{aligned}
& \ln \left(q_{e}-q_{t}\right)=\ln q_{e}-k_{l} t \\
& t / q_{t}=1 / k_{2} q_{e} 2+t / q_{e}
\end{aligned}
$$

where, $q_{t}$ and $q_{e}$ are the amount of dye adsorbed on the adsorbents $\left(\mathrm{mg} \cdot \mathrm{g}^{-1}\right)$ at time $t$ and at equilibrium, respectively. $k_{1}\left(\mathrm{~min}^{-1}\right)$ and $k_{2}\left(\mathrm{~g} \cdot \mathrm{mg}^{-1} \cdot \mathrm{min}^{-1}\right)$ are the rate constants of first order and second order, respectively. Figure 4 shows the kinetics of dyes adsorption on adsorbents ZX and ZXK. For the Lagergren firstorder model, the values of $\mathrm{R}$ are lower than those obtained using the Ho' pseudosecond-order model. This confirms the second order nature of dyes adsorption on adsorbents ZX and ZXK. 

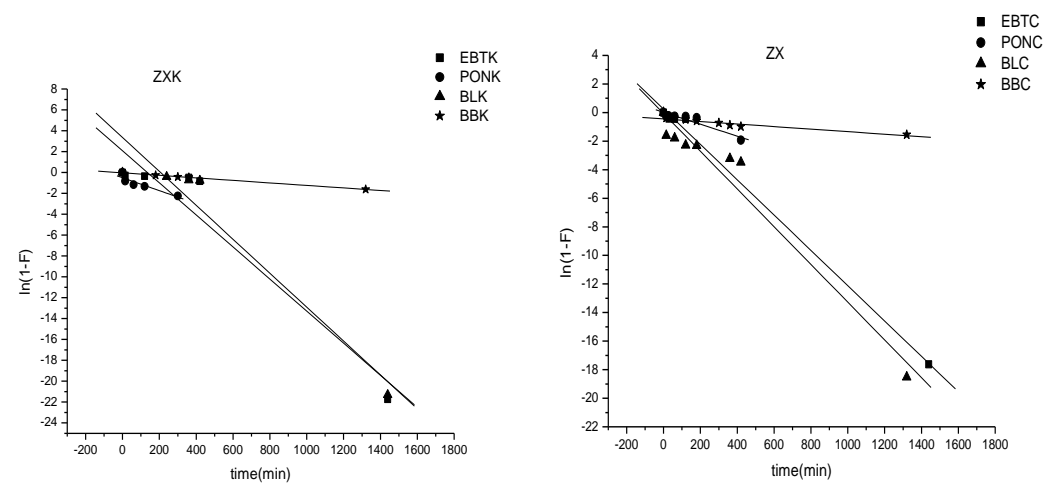

(a) Liquid film
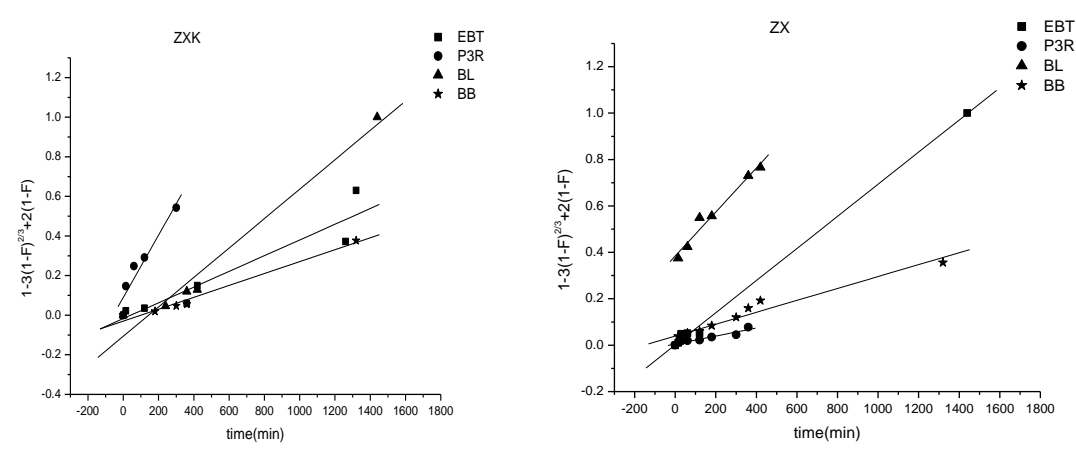

(b) Intraparticle
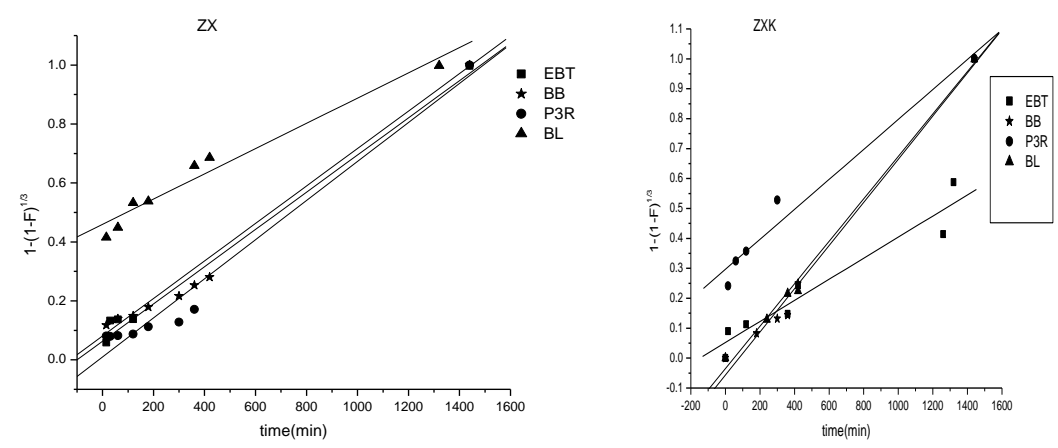

(c) Chemical reaction

Fig. 3. Fitted regression line of dyes on adsorbents ZX and ZXK by three models.

Egypt. J. Chem. 53, No. 3 (2010) 

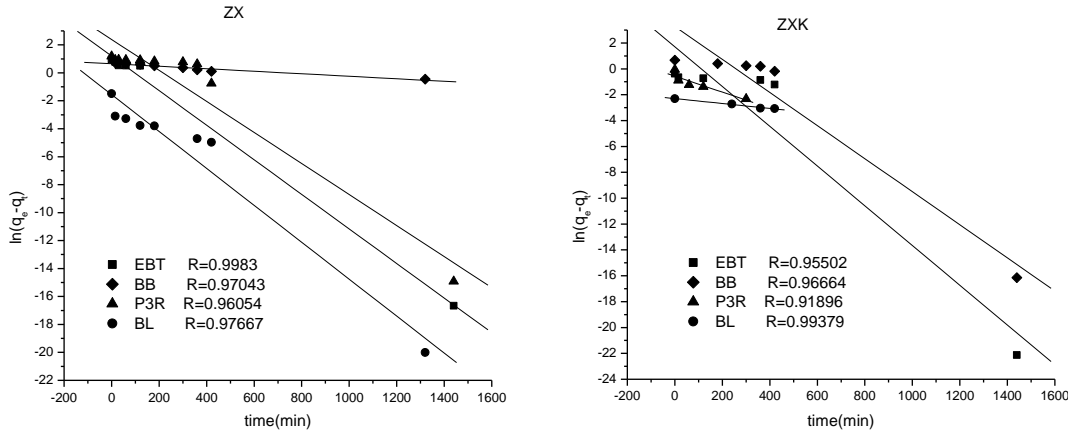

(a) Lagergren first-order model
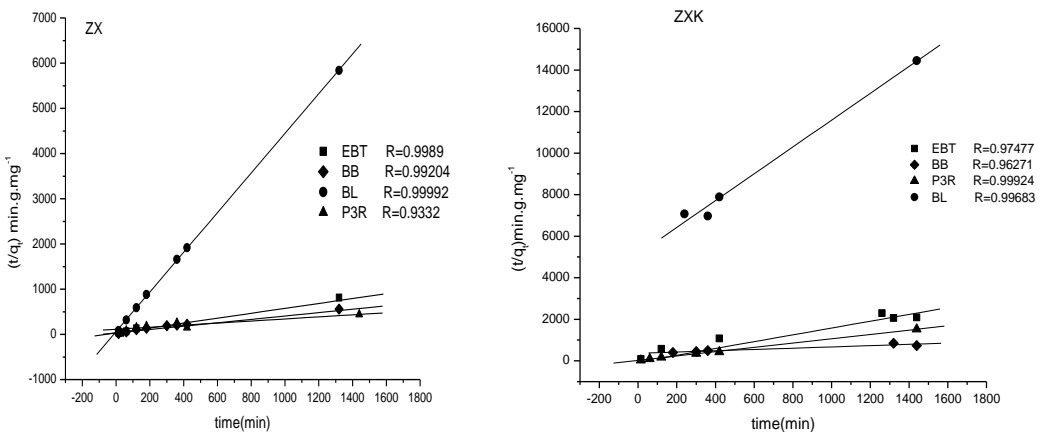

(b)Ho' pseudo-second-order model

Fig. 4. Plots of kinetics of dyes adsorption on adsorbents ZX and ZXK.

\section{Adsorption isotherm}

For the solid-liquid system, the studies of adsorption isotherms are very important to realize information about adsorption capacity of adsorbents. The widely used isotherm equations for evaluating the adsorption equilibrium are Langmuir and Freundlich isotherms. The Langmuir isotherm is obtained under an assumption that the adsorption occurs at a specific homogeneous surface of the adsorbent ${ }^{(2,5,9)}$. The linearly transformed Langmuir isotherm is used to fit the adsorption data in this study and is expressed as:

$$
C_{e} / q_{e}=C_{e} / q_{m}+1 / q_{m} b
$$

where, $C_{e}$ is the equilibrium concentration of the dye in solution $\left(\mathrm{mg} \cdot \mathrm{L}^{-1}\right), q_{e}$ is the amount of dye adsorbed on adsorbents $\left(\mathrm{mg} \cdot \mathrm{g}^{-1}\right)$, and $q_{m}$ and $b$ are the monolayer adsorption capacity $\left(\mathrm{mg} \cdot \mathrm{g}^{-1}\right)$ and the binding constant, respectively. The Freundlich isotherm is an empirical equation which is used for the heterogeneous systems and is represented as ${ }^{(2,5)}$

$$
\lg q_{e}=\lg K_{f}+1 / n \lg C_{e}
$$


where $K_{\mathrm{F}}$ and $n$ are indicative of the extent of the adsorption and the adsorption intensity, respectively. Figure 5 shows the linearized Langmuir and Freundlich adsorption isotherms of the dyes on adsorbents ZXK and ZX with different concenteration. The model parameters obtained from these isotherms are given in Table 3. The apparent equilibrium constant $\left(K_{\mathrm{a}}\right)$ determined by the product of $b$ and $q_{\mathrm{m}}$ can be used as relative indicators of the affinity of adsorbents toward the dyes. It is indicated from these $K_{\mathrm{a}}$ values that the affinity of $\mathrm{ZX}$ for the dyes is higher in comparison of ZXK. In addition, by comparison between the calculated $\mathrm{q}_{\mathrm{m}}$ values in Table 3, it is found that the zeolite prepared from Egyptian kaolin shows smaller adsorption capacity than the commercial one. The maximum monolayer adsorption capacity $\mathrm{q}_{\mathrm{m}}$ is obtained for $\mathrm{BB}$ adsorbed by the prepared zeolite which is approximately $13 \%$ from the value obtained for the commercial zeolite.
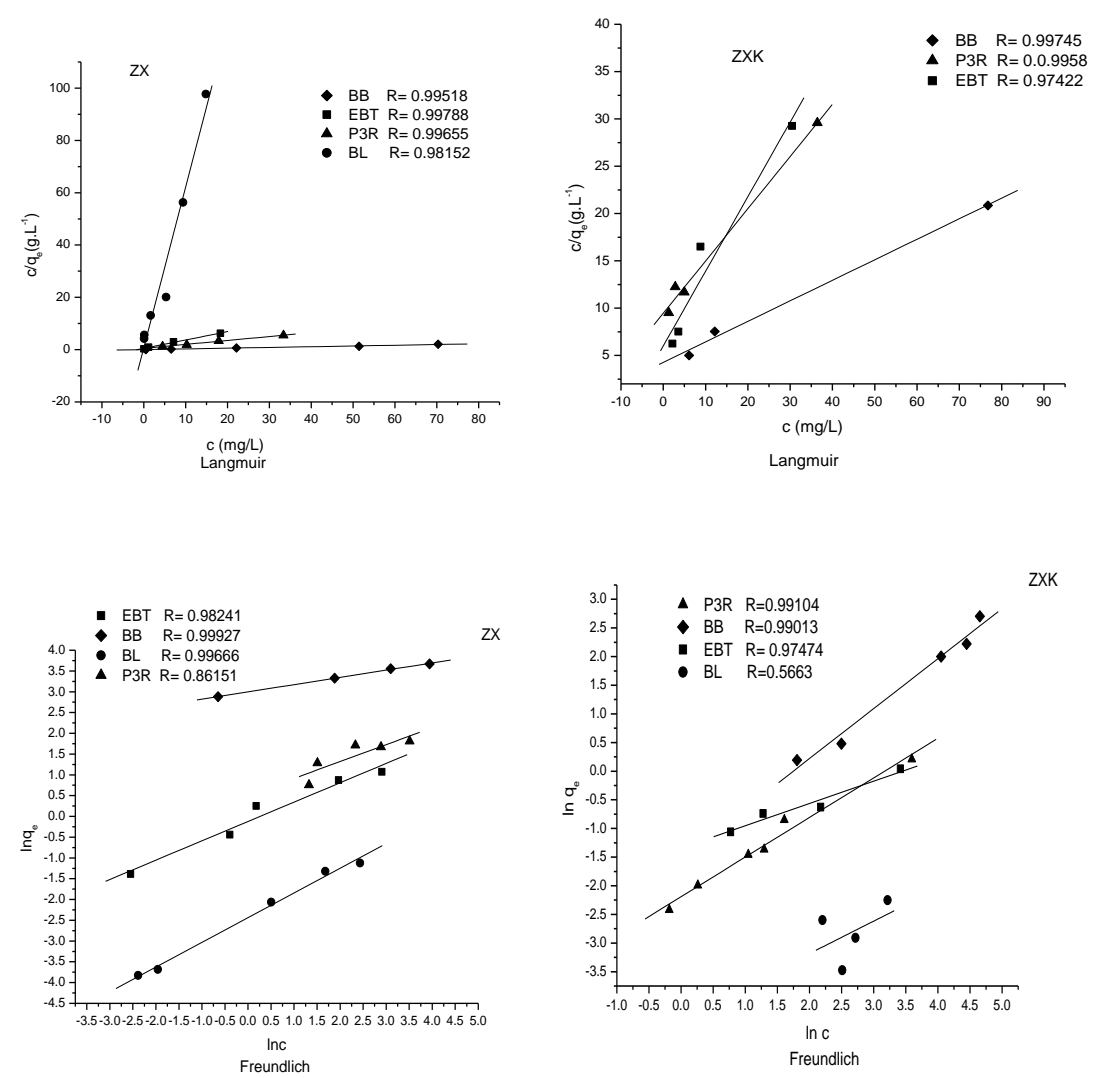

Fig. 5. Experimental dyes adsorption isotherms of adsorbents $\mathrm{ZX}$ and $\mathrm{ZXK}$ with different concentrations.

However, it is worthy to mention that even at the relatively small amount of adsorbed dye molecules per $1 \mathrm{~g}$ of zeolite $\left(\mathrm{q}_{\mathrm{e}}\right)$, both zeolites show high efficiency in removing the dye coloration. Table 3 summarizes the values of molar absorbtivity (e), where the high e values of the dyes under investigation point out strongly colored dye solutions.

Egypt. J. Chem. 53, No. 3 (2010) 
From the results, it was found that the variations of adsorption capacity (i.e., $q_{\mathrm{e}}$ ) had an increasing trend with initial dye concentration increase. This could be due to the powerful driving force provided by the high initial concentrations which overcome the mass transfer resistance between the aqueous and solid phases.

TABLE 3. Langmuir and Freundlich parameters for dyes adsorption on adsorbents ZX and ZXK.

\begin{tabular}{|c|c|c|c|c|c|c|c|c|}
\hline zeolite & & \multicolumn{4}{|c|}{ Langmuir parameters } & \multicolumn{3}{|c|}{ Freundlich Parameters } \\
\hline \multirow{5}{*}{$\mathbf{Z X}$} & Dye & $\begin{array}{c}\text { B } \\
(\text { L.mg } \\
\end{array}$ & $\underset{\left(\mathrm{mg} \mathrm{g}^{-1}\right)}{\mathbf{q}_{\mathrm{m}}}$ & $\mathbf{K}_{\mathbf{a}}$ & $\mathbf{R}$ & $\underset{\left(\mathrm{mg}_{\mathrm{F}} \mathrm{g}^{-1}\right)}{\mathrm{K}_{\mathrm{f}}}$ & $1 / \mathbf{n}$ & $\mathbf{R}$ \\
\hline & $\mathrm{BB}$ & 0.23 & 38.23 & 8.79 & 0.99191 & 7.61 & 0.46 & 0.98414 \\
\hline & $\mathrm{BL}$ & 2.32 & 0.17 & 0.39 & 0.97318 & 0.07 & 0.66 & 0.99652 \\
\hline & EBT & 0.08 & 4.39 & 0.35 & 0.99660 & 0.28 & 0.91 & 0.99894 \\
\hline & P3R & 0.13 & 7.24 & 0.94 & 0.99224 & 0.25 & 0.98 & 0.92427 \\
\hline \multirow{4}{*}{ ZXK } & $\mathrm{BB}$ & 0.05 & 4.65 & 0.23 & 0.99751 & 0.52 & 0.45 & 0.99989 \\
\hline & $\mathrm{BL}$ & - & - & - & - & 0.01 & 0.60 & 0.48287 \\
\hline & EBT & 0.08 & 1.38 & 0.11 & 0.97382 & 0.20 & 0.45 & 0.98178 \\
\hline & P3R & 0.05 & 1.9 & 0.10 & 0.99564 & 0.10 & 0.68 & 0.99958 \\
\hline
\end{tabular}

Adsorption from a solution to the solid surface starts to take place when the dipole or charged species of adsorbent and adsorbate mutually interact with each other. Considering the chemical structures of the investigated dyes given in Table 1, it was found that as the number of sulfonate functional groups increases, the adsorption capacities increase (obviously noticed from both Langmuir and Freundlich parameters). The maximum monolayer adsorption capacity $q_{\mathrm{m}}$ is obtained for BB (4 sulfonate groups) followed by P3R (2 groups) and then EBT (1 group), respectively. Contrary, though BL has 3 sulfonate groups, it shows the least adsorption tendency toward the two zeolites. Its structure shows steric hindrance towards the entry aperture of zeolites pores, leading to difficulty in access to the inside of the zeolite $\mathrm{X}$ and remains only on the external surfaces of these zeolite crystal.
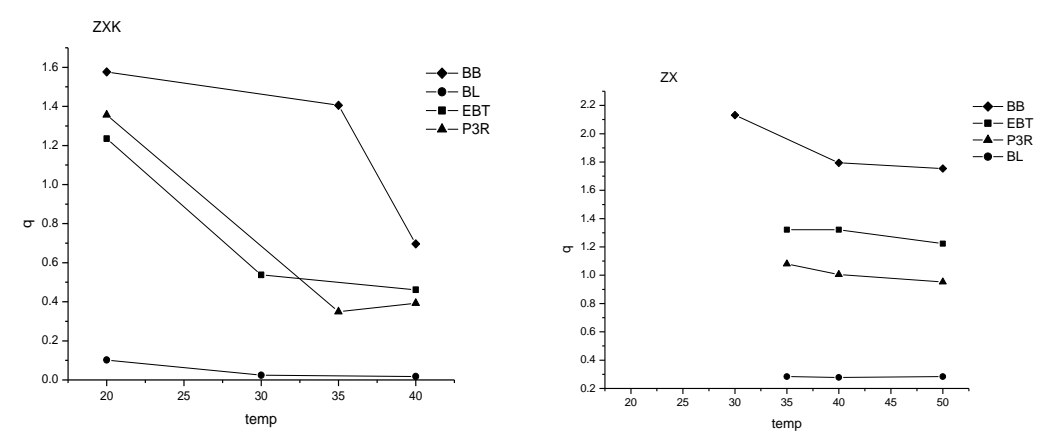

Fig. 6. Effect of temperature on ZX and ZXK. 


\section{Effect of temperature}

It was observed that with the increase in temperature, the values of $q$ become lower, indicating that this interaction is exothermic (confirmed by the increase of temperature during the experiments).

TABLE 4. The amount of dye adsorbed per one gram at different pH values, equilibrium time $=\mathbf{3 0} \mathrm{min}$.

\begin{tabular}{|c|c|c|c|c|c|c|c|c|}
\hline \multirow{2}{*}{ PH } & \multicolumn{2}{|c|}{ P3R } & \multicolumn{2}{c|}{ BB } & \multicolumn{2}{c|}{ EBT } & \multicolumn{2}{c|}{ BL } \\
\cline { 2 - 9 } & ZX & ZXK & ZX & ZXK & ZX & ZXK & ZX & ZXK \\
\hline 11 & 0.34 & 0.42 & 0.25 & 0.41 & 1.85 & 1.85 & 0.07 & 0.18 \\
\hline $\mathrm{H}_{2} \mathrm{O}$ & 0.65 & 0.28 & 0.92 & 0.42 & 0.70 & 0.20 & 0.05 & 0.02 \\
\hline 2.1 & 0.48 & 0.40 & 0.64 & 0.31 & 1.14 & 0.77 & -0.12 & 0.27 \\
\hline
\end{tabular}

\section{Effect of $\mathrm{pH}$}

It was noticed that $\mathrm{pH}$ of the solution doesn't remarkably affect the adsorption capacity towards the different anionic dyes. This can be explained in terms of both zeolite stability and the ionic form of the different dyes. At low $\mathrm{pH}$ value (2.1) the zeolite may undergo slight deformation due to the dissolution of $\mathrm{Al}$ atoms. The distortion of zeolites framework will compensate the decrease in electron density of the dye moiety which are expected to decrease the electrostatic repulsion between dye molecules and zeolite. Contrary at higher $\mathrm{pH}$ the electrostatic repulsion between zeolites and the dyes in their anionic forms leads to decrease the adsorption extent.

\section{Ion exchange effect}

In this paper, the adsorptions of dyes for divalent cations $\left(\mathrm{Mg}^{+2}, \mathrm{Ba}^{+2}\right.$ and $\left.\mathrm{Ca}^{+2}\right)$ exchanged X-zeolites in comparison with their base form in $\mathrm{Na}^{+}$were systematically studied at room temperature. The effects of ion-exchange on the adsorption capacity are examined. Zeolites have negative charge in the entire range $\mathrm{pH}$ (5.4-6.6). Since the anionic dyes have negative sulfonate groups, they are repelled by negatively charged zeolite surface ${ }^{(6)}$. In this experimental section, the surfaces of zeolites were exchanged by $\mathrm{Mg}^{+2}, \mathrm{Ca}^{+2}, \mathrm{Ba}^{+2}$ metal ions. The presence of divalent metal ions leads to generate surface metallic complexes. The formation of these surface complexes allowed us to describe the exchanged ZX-dye interaction as a strong adsorption (perhaps chemisorptions) ruled by the reactive characteristics of sulphonate groups.

TABLE 5. Effect of ion exchange on amount of dye adsorbed per $1 \mathrm{~g}$ on $\mathrm{ZX}$ and $\mathrm{ZXK}$.

\begin{tabular}{|c|c|c|c|c|c|}
\hline \multirow{4}{*}{} & \multicolumn{5}{|c|}{$\boldsymbol{q}_{\mathbf{3 0}}\left(\mathbf{m g . g} \mathbf{~}^{-\mathbf{1}}\right)$} \\
\cline { 2 - 6 } & Dye & Na-X & Ca-X & Ba-X & Mg-X \\
\hline \multirow{4}{*}{ ZX } & EBT & 1.12 & 1.71 & 2.85 & 2.37 \\
\cline { 2 - 6 } & BB & 1.14 & 1.47 & 3.19 & 3.34 \\
\cline { 2 - 6 } & P3R & 0.39 & 0.86 & 4.37 & 2.03 \\
\hline \multirow{4}{*}{ ZXK } & BL & 0.1 & 0.18 & 0.26 & 0.56 \\
\cline { 2 - 6 } & EBT & 0.74 & 1.07 & 2.15 & 1.08 \\
\cline { 2 - 6 } & BB & 1.35 & 1.73 & 4.91 & 2.37 \\
\cline { 2 - 6 } & P3R & 0.23 & 0.48 & 1.27 & 0.83 \\
\hline
\end{tabular}

Egypt. J. Chem. 53, No. 3 (2010) 
From this table, it can be seen that the exchange of sodium ions in zeolite ZX and ZXK by calcium ions led to an increase of the amount of all dyes under investigation. It can also be observed that the adsorption capacity increases generally in the following order;

For ZX; $\mathrm{NaX}<\mathrm{CaX}<\mathrm{MgX}<\mathrm{BaX}$ exception was detected in case of $\mathrm{BL}$ on $\mathrm{Mg}-\mathrm{X}$ For $\mathrm{ZXK} ; \mathrm{NaX}<\mathrm{CaX}<\mathrm{MgX}<\mathrm{BaX}$ exception was detected in case of $\mathrm{BL}$ on $\mathrm{Mg}-\mathrm{X}$

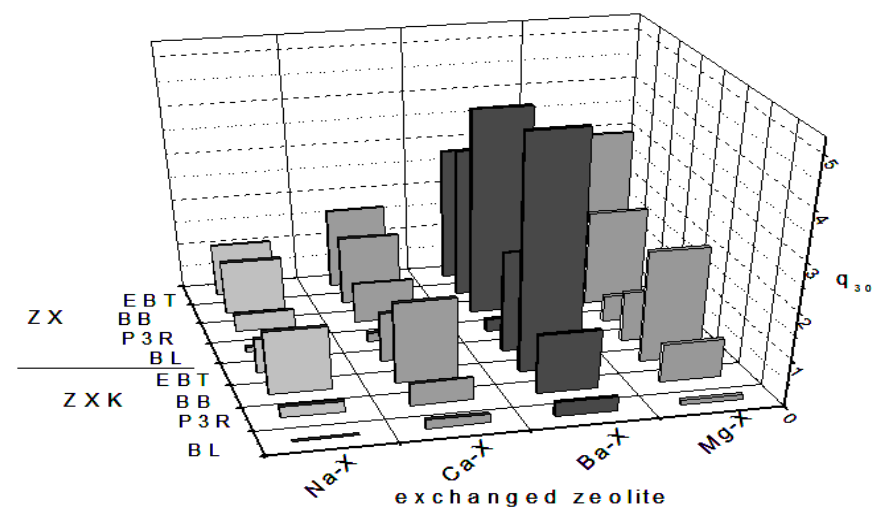

Fig. 7. Effect of ion exchange on amount of dye adsorbed per $1 \mathrm{~g}$ on $\mathrm{ZX}$ and $\mathrm{ZXK}$.

Regeneration

Regeneration of zeolite is also an important issue in zeolite utilization ${ }^{(8)}$. We used high temperature calcination $300^{\circ} \mathrm{C}$ and $550^{\circ} \mathrm{C}$ for removal of organic dyes deposit on zeolite. The regenerated ZXK presents much better recovery in adsorption efficiency than $\mathrm{ZX}$ at $300^{\circ} \mathrm{C}$. Compared with the amount of EBT adsorbed of the fresh ZX (1.76 $\left.\mathrm{mg} . \mathrm{g}^{-1}\right)$, the regenerated $\mathrm{ZX}$ produces $0.02 \mathrm{mg}$. $\mathrm{g}^{-1}$ which is only $1.14 \%$ adsorption efficiency. On the other hand, the amount of EBT adsorbed of the fresh ZXK is $(0.37$ mg. $\mathrm{g}^{-1}$ ), while the regenerated ZXK produces $0.38 \mathrm{mg}$. $\mathrm{g}^{-1}$ which is $102.70 \%$ adsorption efficiency. At $550{ }^{\circ} \mathrm{C}$ the regenerated ZX exhibits negative adsorption, while regenerated ZXK produces $98.5 \%$ adsorption efficiency in the $1^{\text {st }}$ regeneration and $72.5 \%$ in the $2^{\text {nd }}$ regeneration. The decrease in the adsorption capacities for regenerated zeolites at $550{ }^{\circ} \mathrm{C}$ may be due to the pore collapse at elevated temperatures ${ }^{(8)}$. The negative adsorption noticed for the regenerated $\mathrm{ZX}$ at $550{ }^{\circ} \mathrm{C}$ may be due to the adsorption of solvent molecules (water) rather than the organic dye molecules ${ }^{(9)}$.

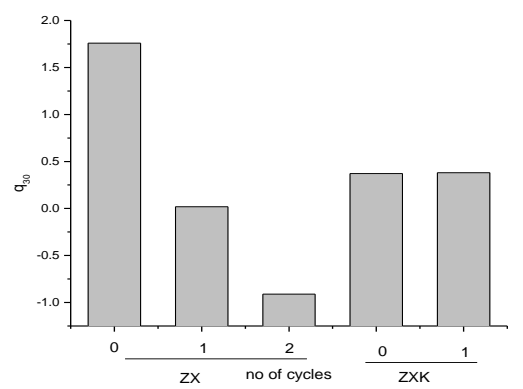

(a) Regeneration at $300{ }^{\circ} \mathrm{C}$

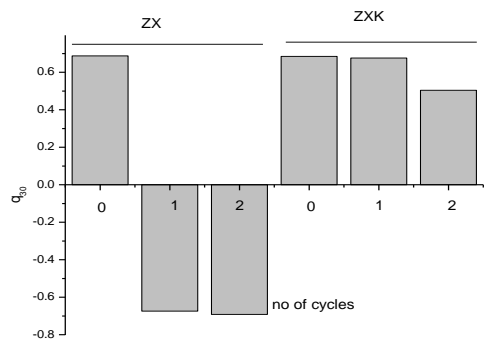

(b)Regeneration at $550{ }^{\circ} \mathrm{C}$

Fig. 8. regeneration at $300^{\circ} \mathrm{C}$ and $550{ }^{\circ} \mathrm{C}$ for both $\mathrm{ZX}$ and $\mathrm{ZXK}$ on EBT. 
Therefore, it is deduced that the used ZXK can be effectively regenerated by calcination and the adsorption capacity restored. Adsorption of dyes on adsorbent will usually be deposited on the surface and pores of solids. High temperature calcination in air results in the decomposition of adsorbed dyes to gases, thus releasing the surface and pores for re- adsorption.

\section{Conclusion}

From the above it can be concluded that the two zeolites ZX or ZXK can be used for the removal of coloured dyes from water. The exchange of sodium ions in zeolite ZX and ZXK by calcium ions led to an increase of the amount of all dyes under investigation. BaX and $\mathrm{BaXK}$ were found to be more capable for adsorption of dyes than all other cation exchanged zeolites. The direct use of ZX was found to be more effective than the zeolite ZXK, but the regenerated ZXK appeared adsorptive capacity more than the ZX one. This was attributed to the incomplete removal of the condensed materials deposited over $\mathrm{ZX}$ zeolite even after heating at 300 or $550^{\circ} \mathrm{C}$ or/and may be due to the adsorption of solvent molecules (water) rather than the organic dye molecules.

\section{References}

1. Yan, C., Wang, C., Yao, J., Zhang, L. and Liu, X., Adsorption of methylene blue on mesoporous carbons prepared using acid- and alkaline-treated zeolite $\mathrm{X}$ as the template. Colloids and Surfaces A: Physicochem. Eng. Aspects, 333, 115 (2009).

2. Chunfeng, W., Jiansheng, L., Lianjun,W., Xiuyun,S. and Jiajia, H., Adsorption of dye from wastewater by zeolites synthesized from fly ash: Kinetic and equilibrium studies, Chin. J. Chem. Eng. 17, 513 (2009).

3. Bobuatong, K. and Limtrakul, J., Effects of the zeolite framework on the adsorption of ethylene and benzene on alkali-exchanged zeolites: an ONIOM study. Applied Catalysis A: General, 253, 49 ( 2003).

4. Tien Tsai, W., Jong Hsien, K. and Chieh Hsu, H., Adsorption of organic compounds from aqueous solution onto the synthesized zeolite. Hazardous Materials, 166, 635 (2009).

5. Kilinc Alpat, S. K., Özbayrak, Ö., Alpat, S. and Akcay, H., The adsorption kinetics and removal of cationic dye, Toluidine Blue $\mathrm{O}$, from aqueous solution with Turkish zeolite. Hazardous Materials, 151, 213(2008).

6. Armagan, B., Turan, M. and Celik, M. S., Equilibrium studies on the adsorption of reactive azo dyes into zeolites. Desalination, 170, 33(2004).

7. Selim, M. M. and Abd El Maksoud, I. H., A process for preparation faujasite NaX zeolite from Egyptian kaolin, Egyptian Patent No. 23590 (2006).

8. Wang, S., Li, H., Xie, S., Liu, S. and Xu, L., Physical and chemical regeneration of zeolitic adsorbents for dye removal in wastewater treatment. Chemosphere, 65, 82 (2006).

Egypt. J. Chem. 53, No. 3 (2010) 
9. Ozdemir, O., Armagan, B., Turan, M. and Çelik, M. S., Comparison of the adsorption characteristics of azo-reactive dyes on mezoporous minerals. Dyes and Pigments, 62, 49 (2004).

10. Qiu, M., Qian, C., Xu, J., Wu, J. and Wang, G., Studies on the adsorption of dyes into clinoptilolite. Desalination, 243, 286(2009).

11. Wang, S., Li, H. and Xu, L., Application of zeolite MCM-22 for basic dye removal from wastewater. Journal of Colloid and Interface Science, 295, 71 (2006).

12. Wang, S. and Peng, Y., Natural zeolites as effective adsorbents in water and wastewater treatment. Chemical Engineering Journal, 156, 11 (2010). Wang, S.B., Boyjoo, Y., Choueib, A., Zhu, Z.H., Removal of dyes from aqueous solution using fly ash and red mud. Water Research, 39 , 129(2005).

13. Milton, Robert. M. and Bufflo, N.Y., Molecula-Sieve adsorbents, United States Patent No. 2, 882, 44.

(Received 14/7/2010;

accepted 29/7/2010) 


$$
\begin{aligned}
& \text { اســـخدام الزيوليــت الاصــطناعى لإزالـــة الأصــبـاغ ألانيونيــة } \\
& \text { رشا محمود عبد الوهاب" ، دعاء محمد محمد المكاوى" ، عبد الفتاح بسطاوى }
\end{aligned}
$$

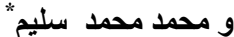

$$
\begin{aligned}
& \text { قسم الكيميـاء الفيزيقيـة ـ المركز القومي للبحوث و "قسم الكيميـاء ـ كليـة العلوم ـ }
\end{aligned}
$$

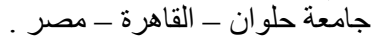

تم دراسـة إز الـة الملوثات العضوية الملونة القابلة للذوبان في المساء. وقد اجريت

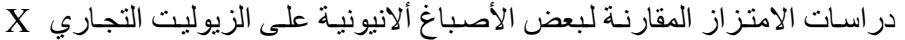

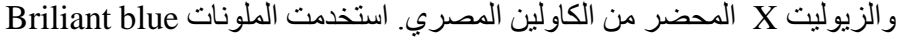

FCF (BL), Briliant black PN (BB), Eriochrome black T (EBT) and Ponceau 3R (P3R).

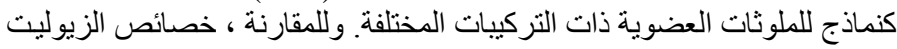

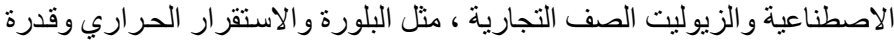

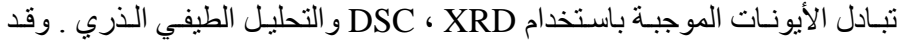

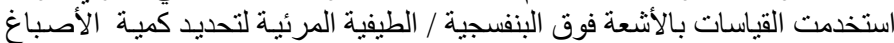

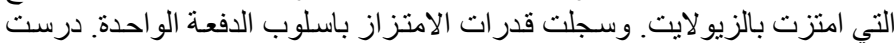

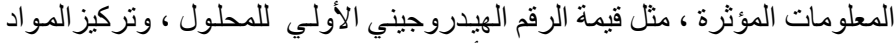

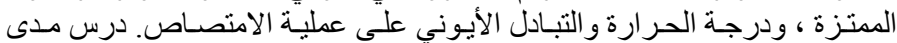

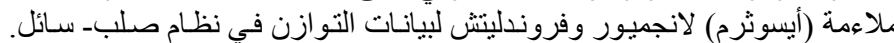

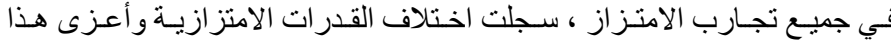

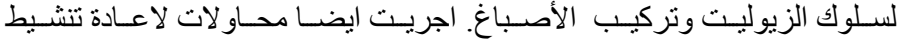

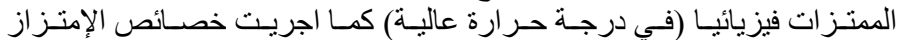

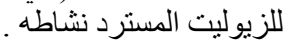

